\title{
Sexual dimorphism in cranial morphology among modern South Africans
}

Gabriele C Krüger, BSc (Honours) $^{\mathrm{a} *}$; Ericka N L’Abbé, PhD, D-ABFA ${ }^{\mathrm{a}}$; Kyra E Stull, PhD ${ }^{\mathrm{b}}$; Michael W Kenyhercz, MS

a Department of Anatomy, Faculty of Health Sciences, University of Pretoria, Private Bag X323, Arcadia, 0007, South Africa

${ }^{\mathrm{b}}$ Department of Anthropology, Idaho State University, 921 South 8th Avenue, Stop 8005, Pocatello, ID 83209

${ }^{\mathrm{c}}$ Department of Anthropology, University of Tennessee Knoxville, 250 South Stadium Hall, Knoxville, TN 37996

* Corresponding author: Gabriele C. Krüger

Department of Anatomy, University of Pretoria

Private Bag x323, Arcadia 0007 South Africa

Tel.: +27 82372 0136/ 12319 2235; Fax: +27 123192240 .

E-mail address: gabi_iam@yahoo.com

\begin{abstract}
Pattern-expressions of morphoscopic cranial traits vary across populations with classification accuracies being highly dependent on the reference collection to which unknown skulls are compared. Despite recent developments in population-specific standards for South Africans, researchers have not addressed the accuracy of morphological methods. Several studies demonstrate differences in sexual dimorphism between South Africans and North Americans, warranting a need to re-evaluate sex estimation methods in South Africa. The purpose of this study was to test the reliability and accuracy of the Walker (2008) method and to examine patterns of sexual dimorphism among South Africans.
\end{abstract}

A total of 245 modern black and white South African male and female crania from the Pretoria Bone Collection, University of Pretoria, were scored using the Walker (2008) methodology. Cohen's Kappa was used to evaluate reliability of the method and percent correct assessed validity of the method. Logistic regression was utilised to create modified population-specific formulae.

Inter- and intra-observer agreement was moderate to excellent (0.60-0.90), except for the mental eminence (0.40). The percent correct results for sex were $80 \%$ or higher for combinations of glabella, mastoid and menton and between $68 \%$ and $73 \%$ for menton, mastoid, orbital and nuchal margin using logistic equations 
of Walker (2008). White males had the highest (94-97\%) and white females had the lowest (31-62\%) percent correct.

The low accuracies obtained when using Walker (2008) emphasized the need for population-specific sex estimation models. Modified formulae for South Africans were created, yielding higher classification rates (84-93\%) than when North American standards were employed.

KEYWORDS: sex estimation; cranial variation; morphoscopic traits; percent correct; ordinal logistic regression; 


\section{Introduction}

As part of the process of presumptive identification, a biological profile is constructed from skeletal remains and consists of an estimation of age-at-death, sex, ancestry and stature. Accurate sex estimation is based on interpreting and quantifying the expression of sexual dimorphism in a population [1, 2]. While Aḉsádi \& Nemeskéri [3] originally developed the method of using diagrams to score morphological traits of the cranium from -2 (hyperfeminine) to +2 (hypermasculine), with 0 representing androgynous [3], Walker improved the repeatability of the method with simpler line diagrams that encompassed a larger range of human variation. The new diagrams were utilised by Buikstra and Ubelaker [4] before Walker [5] went one step further and applied a variety of statistical tests, including ordinal logistic regression, to the scores to develop population-specific functions for sex estimation among North Americans [5].

Walker's statistical approach has been tested on numerous samples inclusive of modern EuropeanAmericans, African-Americans, English, and ancient Native Americans [5]. The reported correct classification rates for single traits ranged from $69-83 \%$ in modern samples and up to $70 \%$ in the Native American sample [5, 6]. The mastoid process and glabellar region were the most accurate in both modern and prehistoric groups. When using multiple traits, the accuracy rates increased to $89 \%$ in modern samples; however, the degree and pattern of expression of the five traits were found to vary across populations and geography $[5,6,7,8]$. English populations were more gracile than the modern African- and European-Americans; European-Americans had more pronounced glabellar regions, and the African-Americans displayed more prominent mental eminences. The variation noted among populations reiterates the need for population-specific formulae.

Overall, classification accuracies depend on the variation and degree of sexual dimorphism displayed in the reference collection [9]. Craniometric studies on South African groups noted considerably lower levels of sexual dimorphism than in North American groups [10,11]. Overall, South African black males are relatively smaller and South African black females are relatively larger when compared to their North American counterparts [10, 11]. Greater size differences exist between the crania of South African white males and females compared to South African black males and females, which suggests a greater degree of sexual dimorphism in South African whites as compared to blacks [11].

The purpose of this study are to test the accuracy of the Walker [5] method, to assess the amount of sexual dimorphism in terms of the five morphological traits following Walker [5], and to determine the practicality of the technique when applied to black and white South Africans. Additionally, due to a high correlation noted 
between metric and nonmetric cranial traits in North Americans [12], this study will compare morphological and osteometric sex estimation in the crania of South Africans using polyserial correlations.

\section{Materials and Methods}

A stratified random sample of 245 crania from the Pretoria Bone Collection (PBC) were scored according to the five standard morphoscopic traits for the cranium as presented in Walker [5] without knowledge of the demographics. The five morphoscopic cranial traits include the nuchal crest, mastoid process, glabella, supraorbital margin and the mental eminence $[3,4,5]$. An individual was excluded from the sample if the age was less than 18 years; absence of one of the five traits; excessive antemortem tooth loss (greater than 6 teeth in one quadrant); and/or bone pathology. The sample was evenly distributed with ages ranging from 21 to 91 years with a mean age of 59 years (Table 1). The PBC, housed in the Department of Anatomy at the University of Pretoria, is one of the most contemporary skeletal samples in South Africa with birth dates ranging from 18631996 [13-15]. Because the sample includes individuals with birth dates between 1898 and 1985, the sample is a good representation of modern variation within the population.

\begin{tabular}{lccc}
\hline \multicolumn{4}{l}{ TABLE 1. Sample sizes and abbreviations for each ancestry and sex group } \\
\hline & $\mathbf{n}$ & Mean Age & Abbreviation \\
\hline Black Females & 60 & 48.1 & $\mathrm{BF}$ \\
Black Males & 62 & 51.9 & $\mathrm{BM}$ \\
White Females & 61 & 69.3 & $\mathrm{WF}$ \\
White Males & 62 & 67.4 & $\mathrm{WM}$ \\
\hline
\end{tabular}

The first author (GCK) re-scored 15 randomly selected skulls to evaluate the intra-observer agreement. In addition, two observers of differing experience (doctoral and undergraduate honours levels) scored the same 15 skulls to assess inter-observer agreement. The intra- and inter-observer agreement, analysed with Cohen's kappa, was conducted in order to evaluate consistency within and between raters [16]. If raters are in complete agreement, then $\kappa=1$. If no agreement is found among raters (other than what would be expected by chance) then $\kappa=0$. Values less than 0.40 represent poor agreement beyond chance, values between 0.40 and 0.75 indicate medium or good association, and values greater than 0.75 may be taken as excellent agreement between observers [17].

Following Walker [5], six logistic regression equations based on several combinations of weighted features were used to estimate the sex of each individual. Percent correct was used to gauge the relative accuracy of the Walker [5] logistic regression equations when applied to South African sex and sex-ancestry groups. Trait 
frequencies for each of the ordinal scores were calculated by sex and a combined sex and ancestry to analyse the distribution of scores within the sample. Chi-squared test were utilised to assess sex differences as well as ancestry differences between the sexes for all five traits. In order to compare the use of craniometrics and visual assessment in sex estimation, polyserial correlations, which examine the relationship between ordinal and continuous variables, were conducted. The resulting correlation coefficients either indicate a positive or negative relationship, which can be weak $(<0.3)$, moderate $(0.3-0.7)$ or strong $(>0.7)$; a stronger correlation indicates a higher degree of covariation [18]. Two sets of Forward Wilks' stepwise selected craniometric measurements obtained with a linear discriminant analysis were compared to the scores obtained for each of the five Walker [5] variables. The first set of variables was separated by sex and the second set by sex and ancestry to follow the ordinal logistic regression methodology previously described.

Ordinal logistic regression was used to calculate the probability of correctly classifying the sex of individuals based on the different morphological expressions of the five traits [19]. Furthermore, ordinal logistic regression used weighted combinations of values on the scores of the non-metric traits to determine the variable's significance when estimating sex of an individual [20,21]. To confidently utilize logistic regression, an equal relationship between each pair of outcome groups is assumed and is termed the proportional odds or parallel regression assumption.

\section{Results}

\section{Inter- and Intra-observer agreement}

Inter-observer assessment resulted in substantial to excellent agreement for all five traits (36\% to $90 \%)$. For both observers, the mental eminence had the lowest agreement (36\%) and the glabella and mastoid had the highest agreements (72-88\% and $80-90 \%$, respectively). The intra-observer agreement had a greater range of agreement (71-96\%) than the inter-observer agreements; results yielded almost perfect agreement of the glabella, mastoid process and supraorbital margin and substantial agreement of the mental eminence and nuchal crest.

\section{Validating Walker [5] for South African populations}

For the Walker [5] logistic regression equations, sex classified between $68 \%$ and $84 \%$ correctly (Table 2). 


\begin{tabular}{lcccc}
\hline \multirow{2}{*}{$\begin{array}{l}\text { TABLE 2. Percent correct (\%) for Equations 1-6 when only sex is considered. Sex bias was } \\
\text { determined by subtracting the percent correct of females from the percent correct of males. }\end{array}$} \\
\cline { 2 - 4 } & \multicolumn{3}{c}{ Percent correct } & \multirow{2}{*}{ Sex Bias (\%) } \\
\cline { 2 - 4 } Equation & Males & Females & Combined & \\
\cline { 1 - 4 } 1 (glabella, mastoid, menton) & 92 & 76 & 84 & 16 \\
2 (glabella, mastoid) & 94 & 67 & 80 & 27 \\
3 (glabella, menton) & 90 & 70 & 80 & 20 \\
4 (mastoid, menton) & 94 & 44 & 69 & 50 \\
5 (orbit, menton) & 90 & 45 & 68 & 45 \\
6 (nuchal, mastoid) & 93 & 53 & 73 & 40 \\
\hline
\end{tabular}

For all equations, females presented with substantially lower accuracies than males. When sex and ancestry were examined together, correct classification was lowest for white females (31-62\%); highest for white males (94-97\%); and intermediate for black males (87-90\%) and black females (55-90\%) (Table 3).

TABLE 3. Percent correct (\%) for Equations 1-6 when sex and ancestry are considered. Sex bias was determined by subtracting the percent correct of females from the percent correct of males.

\begin{tabular}{|c|c|c|c|c|c|c|c|}
\hline \multirow[b]{2}{*}{ Equation } & \multicolumn{5}{|c|}{ Percent correct } & \multicolumn{2}{|c|}{ Sex Bias (\%) } \\
\hline & $B M$ & $B F$ & $W M$ & $W F$ & Combined & Black & White \\
\hline 1 (glabella, mastoid, menton) & 87 & 90 & 97 & 62 & 84 & -3 & 35 \\
\hline 2 (glabella, mastoid) & 90 & 87 & 97 & 48 & 80 & 3 & 49 \\
\hline 3 (glabella, menton) & 84 & 83 & 95 & 57 & 80 & 1 & 38 \\
\hline 4 (mastoid, menton) & 92 & 55 & 95 & 33 & 69 & 37 & 62 \\
\hline 5 (orbit, menton) & 87 & 58 & 94 & 31 & 68 & 29 & 63 \\
\hline 6 (nuchal, mastoid) & 89 & 70 & 97 & 36 & 73 & 19 & 61 \\
\hline
\end{tabular}

\section{Frequencies and correlations}

Females generally display individual trait scores of 1- 3 and males typically display individual trait scores of 3-5 (Table 4). In particular, white males demonstrate the greatest incidence of a score of 5 and black females show the greatest incidence of a score of 1 .

\begin{tabular}{|c|c|c|c|c|c|c|}
\hline & \multirow{2}{*}{ Trait } & \multicolumn{5}{|c|}{ Trait score } \\
\hline & & 1 & 2 & 3 & 4 & 5 \\
\hline \multirow{5}{*}{ Male } & Glabella & 1 & 27 & 28 & 25 & 19 \\
\hline & Mastoid & 0 & 8 & 27 & 37 & 28 \\
\hline & Mental & 2 & 15 & 40 & 40 & 3 \\
\hline & Nuchal & 1 & 13 & 31 & 31 & 23 \\
\hline & Orbit & 8 & 21 & 30 & 27 & 14 \\
\hline \multirow{5}{*}{ Female } & Glabella & 45 & 47 & 6 & 1 & 1 \\
\hline & Mastoid & 15 & 42 & 33 & 8 & 2 \\
\hline & Mental & 12 & 46 & 35 & 7 & 0 \\
\hline & Nuchal & 15 & 40 & 36 & 8 & 1 \\
\hline & Orbit & 23 & 43 & 25 & 7 & 2 \\
\hline
\end{tabular}


However, a large percentage of both sexes presented with scores of 3 for most of the traits; black males and white females had more scores of 3 than the other two groups (Table 5).

\begin{tabular}{|c|c|c|c|c|c|c|}
\hline \multicolumn{7}{|c|}{$\begin{array}{l}\text { TABLE 5. Frequencies (\%) for each trait score when separated into ancestry and sex. Bold indicates the highest frequency } \\
\text { for each trait. }\end{array}$} \\
\hline \multirow{6}{*}{ BF } & \multirow{2}{*}{$\begin{array}{c}\text { Trait } \\
\text { Glabella }\end{array}$} & 1 & 2 & 3 & 4 & 5 \\
\hline & & 65 & 32 & 3 & 0 & 0 \\
\hline & Mastoid & 22 & 50 & 22 & 5 & 2 \\
\hline & Mental & 20 & 47 & 32 & 2 & 0 \\
\hline & Nuchal & 25 & 48 & 27 & 0 & 0 \\
\hline & Orbit & 37 & 52 & 8 & 3 & 0 \\
\hline \multirow{5}{*}{$\mathbf{B M}$} & Glabella & 2 & 40 & 35 & 18 & 5 \\
\hline & Mastoid & 0 & 11 & 32 & 39 & 18 \\
\hline & Mental & 3 & 21 & 39 & 34 & 3 \\
\hline & Nuchal & 2 & 23 & 48 & 27 & 0 \\
\hline & Orbit & 11 & 23 & 34 & 19 & 13 \\
\hline \multirow{5}{*}{$\mathbf{W F}$} & Glabella & 26 & 62 & 8 & 2 & 2 \\
\hline & Mastoid & 8 & 34 & 44 & 11 & 2 \\
\hline & Mental & 3 & 46 & 38 & 13 & 0 \\
\hline & Nuchal & 5 & 33 & 44 & 16 & 2 \\
\hline & Orbit & 10 & 34 & 41 & 10 & 5 \\
\hline \multirow{5}{*}{$\mathbf{W M}$} & Glabella & 0 & 13 & 21 & 32 & 34 \\
\hline & Mastoid & 0 & 5 & 21 & 35 & 39 \\
\hline & Mental & 2 & 8 & 40 & 47 & 3 \\
\hline & Nuchal & 0 & 3 & 15 & 35 & 47 \\
\hline & Orbit & 5 & 19 & 26 & 35 & 15 \\
\hline
\end{tabular}

Polyserial correlations illustrated strong positive relationships between mastoid height (measurement) and mastoid process (morphological variable) and between basion-nasion length (measurement) and glabella (morphological trait). Furthermore, each of the ordinal traits has at least one moderately strong relationship with a craniometric variable (Tables 6-7).

TABLE 6. Polyserial correlation between craniometric variables and ordinal cranial traits. Craniometric measurements were selected based on a Forward Wilks' stepwise selection for distinguishing between black and white males and females. Bold indicates the strongest correlations.

Craniometric variables

\begin{tabular}{|c|c|c|c|c|c|c|c|c|c|c|}
\hline Ordinal Traits & GOL & $M A B$ & $B N L$ & $D K B$ & $M L T$ & $M D H$ & $F O L$ & $N L H$ & $N L B$ & $G N I$ \\
\hline Glabella & $0.402 * *$ & $0.526 * *$ & $0.702 * * *$ & $0.010^{*}$ & $0.464 * *$ & $0.611 * *$ & $0.239 *$ & $0.487 * *$ & $0.056^{*}$ & $0.035^{*}$ \\
\hline Mastoid & $0.226^{*}$ & $0.271 *$ & $0.405^{* *}$ & $-0.166^{*}$ & $0.089 *$ & $0.832 * * *$ & $-0.056^{*}$ & $0.564 * *$ & $-0.019^{*}$ & $-0.181^{*}$ \\
\hline Mental & $0.296^{*}$ & $0.657 * *$ & $0.695 * *$ & $-0.164 *$ & $0.269 *$ & $0.431 * *$ & $-0.117^{*}$ & $0.358 * *$ & $-0.183^{*}$ & $0.073^{*}$ \\
\hline Nuchal & 0.250 * & $0.080 *$ & $0.549 * *$ & $-0.088^{*}$ & $0.361 * *$ & $0.378 * *$ & $0.010^{*}$ & $0.481 * *$ & $0.045^{*}$ & $-0.075^{*}$ \\
\hline Orbit & $0.402 * *$ & $0.571 * *$ & $0.567 * *$ & $0.134^{*}$ & $0.291 *$ & $0.588 * *$ & $0.004^{*}$ & $0.398 * *$ & $0.058 *$ & $0.003^{*}$ \\
\hline
\end{tabular}

‘***’ - values indicate strong correlation $(>0.7) ;$ ‘**’ moderate correlation $(0.3-0.7) ;$; ${ }^{*}$ ’ weak correlation $(<0.3)$; 


\begin{tabular}{|c|c|c|c|c|c|c|c|c|c|}
\hline \multirow[b]{2}{*}{ Ordinal Traits } & \multicolumn{9}{|c|}{ Craniometric variables } \\
\hline & $B N L$ & $M D H$ & FOL & $B B H$ & $B P L$ & $M A L$ & $W F B$ & $D K B$ & $U F B R$ \\
\hline Glabella & $0.702 * * *$ & $0.611 * *$ & $0.239 *$ & $0.514 * *$ & $0.302 * *$ & $0.277^{*}$ & $-0.139 *$ & $0.010^{*}$ & $0.046^{*}$ \\
\hline Mastoid & $0.405 * *$ & $0.832 * * *$ & $-0.056^{*}$ & $0.430 * *$ & $0.063^{*}$ & $0.069 *$ & $-0.111^{*}$ & $-0.166^{*}$ & $-0.131^{*}$ \\
\hline Mental & $0.695 * *$ & $0.431 * *$ & $-0.117^{*}$ & $0.551 * *$ & $0.332 * *$ & $0.300 * *$ & $-0.212 *$ & $-0.164^{*}$ & $-0.070^{*}$ \\
\hline Nuchal & $0.549 * *$ & $0.378 * *$ & $0.010^{*}$ & $0.456 * *$ & $0.170^{*}$ & $0.239 *$ & $-0.100^{*}$ & $-0.088^{*}$ & $-0.010^{*}$ \\
\hline Orbit & $0.567 * *$ & $0.588 * *$ & $0.004 *$ & $0.652 * *$ & $0.314 *$ & $0.326 * *$ & $-0.054 *$ & $0.134 *$ & $0.176^{*}$ \\
\hline
\end{tabular}

‘***' - values indicate strong correlation $(>0.7) ;$ ‘**' - moderate correlation $(0.3-0.7)$; ‘* - weak correlation $(<0.3)$;

\section{Population-specific formulae for South Africans}

Chi-squared tests revealed significant differences between the sexes for all traits $(<0.001)$. Ancestry was significantly different between all traits with the exception of the mental eminence and supra-orbital margin between males groups ( $\mathrm{p}=0.268$ and 0.246 , respectively) (Table 8 ). The poor classification results using the Walker formulae, the obvious sex bias, and the results of the chi-squared tests, warranted the creation of population and ancestry specific formulae.

\begin{tabular}{|c|c|c|c|c|}
\hline \multicolumn{5}{|c|}{$\begin{array}{l}\text { TABLE } 8 \text {. Sex-specific, ancestry differences in cranial trait scores. Statistically significan } \\
\text { ancestry differences are in bold. }\end{array}$} \\
\hline \multirow{3}{*}{ Glabella } & & Average difference ${ }^{a}$ & $\chi^{2}$ & $P$ \\
\hline & Males & 1.27 & 34.09 & $<0.001$ \\
\hline & Females & 0.54 & 19.61 & $<0.001$ \\
\hline \multirow{2}{*}{ Mastoid } & Males & 0.52 & 9.43 & $<0.05$ \\
\hline & Females & 0.49 & 11.64 & $<0.05$ \\
\hline \multirow{2}{*}{ Mental } & Males & 0.29 & 5.19 & 0.268 \\
\hline & Females & 0.47 & 13.76 & $<0.01$ \\
\hline \multirow{2}{*}{ Nuchal } & Males & 1.24 & 50.95 & $<0.001$ \\
\hline & Females & 0.77 & 24.03 & $<0.001$ \\
\hline \multirow{2}{*}{ Orbit } & Males & 0.35 & 5.43 & 0.246 \\
\hline & Females & 0.88 & 29.39 & $<0.001$ \\
\hline
\end{tabular}

${ }_{n}^{\text {a }}$ Average difference was determined by subtracting the average trait score for females from the average trait score for males.

$\chi^{2}$ is the value comparing the frequency distributions of the traits in each population.

$P$ is the probability associated with the $\chi^{2}$ value. 
Modified equations were created for black and white South Africans and included different combinations of the five morphoscopic traits for both ancestry groups. For white South Africans, the glabella added the most proportional odds to the ordinal logistic regression (8.434), followed by the nuchal crest (7.930). The remaining three traits (mastoid process, metal eminence and supra-orbital margin) were not significant in combination for distinguishing between white males and females and were removed from the equation. The equation for estimating sex for black South Africans combined three traits (glabella, mastoid process and supra-orbital margin) and received the most proportional odds from the glabella (4.842), followed by the mastoid process (4.201) and supra-orbital margin (2.072). The nuchal crest and mental eminence were not significant and were subsequently removed from the equation. In addition to the equations created for white and black South Africans separately, the original Walker [5] combinations of traits were adjusted for estimating sex from each of the two South Africans ancestry groups. The modified formulae were created for ease of application in forensic cases specific to South Africa and achieved accuracy rates that ranged between $73 \%$ and $93 \%$. For most equations, white South Africans had higher correct classifications than black individuals. The exceptions include the combinations of mastoid process and mental eminence and the equation using supra-orbital margin and mental eminence, where black South Africans obtained the higher classification accuracies (Tables 9-10).

\begin{tabular}{|c|c|c|c|c|}
\hline \multirow[b]{2}{*}{ Population-specific ordinal logistic regression formulae } & \multicolumn{3}{|c|}{ Accuracy (\%) } & \multirow{2}{*}{ Sex Bias (\%) } \\
\hline & Males & Females & Combined (CV) & \\
\hline $\mathrm{Y}=($ glabella $\mathrm{x}-2.1323)+($ nuchal $\mathrm{x}-2.0707)+\mathbf{1 3 . 2 3 1 7}^{\mathrm{a}}$ & 89 & 96 & 93 & -7 \\
\hline $\mathrm{Y}=($ glabella $\mathrm{x}-1.6572)+($ mastoid $\mathrm{x}-1.2428)+\mathbf{8 . 7 3 0 4}$ & 91 & 85 & 86 & 6 \\
\hline$Y=($ glabella $x-1.8097)+($ mental $x-0.6907)+7.0718$ & 88 & 86 & 86 & 2 \\
\hline $\mathrm{Y}=($ mastoid $\mathrm{x}-1.4610)+($ mental $\mathrm{x}-0.8981)+7.5610$ & 81 & 81 & 80 & 0 \\
\hline $\mathrm{Y}=($ orbit $\mathrm{x}-0.4445)+($ mental $\mathrm{x}-1.1665)+4.8563$ & 75 & 71 & 73 & 4 \\
\hline$Y=($ nuchal $x-1.5690)+($ mastoid $x-1.2048)+9.5121$ & 82 & 88 & 83 & -6 \\
\hline
\end{tabular}

Bold numbers indicate the constant for each of the equations.

a Supra-orbital margin, mastoid process, and mental eminence variables removed as differences between males and females were not significant ( $p=0.56, p=0.09$ and $p=0.92$, respectively). 


\begin{tabular}{|c|c|c|c|c|}
\hline \multirow[b]{2}{*}{ Population-specific ordinal logistic regression formulae } & \multicolumn{3}{|c|}{ Accuracy (\%) } & \multirow{2}{*}{ Sex Bias (\%) } \\
\hline & Males & Females & Combined (CV) & \\
\hline $\mathrm{Y}=($ glabella $\mathrm{x}-1.5774)+($ mastoid $\mathrm{x}-1.4353)+($ orbit $\mathrm{x}-0.7284)+\mathbf{8 . 6 3 6 9}^{\mathrm{a}}$ & 86 & 86 & 84 & 0 \\
\hline$Y=($ glabella $x-1.675)+($ mastoid $x-1.3374)+($ mental $x-0.6798)+\mathbf{8 . 7 1 0 8}$ & 88 & 90 & 84 & -2 \\
\hline $\mathrm{Y}=($ glabella $\mathrm{x}-1.8320)+($ mastoid $\mathrm{x}-1.5042)+7.6887$ & 85 & 91 & 85 & -6 \\
\hline $\mathrm{Y}=($ glabella $\mathrm{x}-1.8146)+($ mental $\mathrm{x}-1.1155)+\mathbf{6 . 3 2 3 7}$ & 83 & 79 & 81 & 4 \\
\hline$Y=($ mastoid $x-1.4885)+($ mental $x-0.9747)+6.6757$ & 84 & 78 & 81 & 6 \\
\hline$Y=($ orbit $x-1.1585)+($ mental $x-1.3446)+6.2090$ & 75 & 77 & 75 & -2 \\
\hline $\mathrm{Y}=($ nuchal $\mathrm{x}-1.3156)+($ mastoid $\mathrm{x}-1.3425)+\mathbf{7 . 0 9 9 7}$ & 84 & 78 & 81 & 6 \\
\hline
\end{tabular}

Bold numbers indicate the constant for each of the equations.

${ }_{\text {a }}$ Mental eminence and nuchal crest variables removed as differences between males and females were not significant ( $p=0.08$ and $p=0.23$, respectively).

\section{Discussion}

While recent research has demonstrated that postcrania outperform the skull in sex estimation [22], the skull is the most frequently recovered element in forensic cases in South Africa (2012 Annual Report, Forensic Anthropology Research Centre, University of Pretoria, South Africa). The high level of inter- and intra-observer agreement for the glabella, mastoid process and nuchal crest in this study suggest that these variables are reliable to use as sex indicators among South Africans. Additionally, the glabella, mastoid process, and nuchal crest contributed the highest proportional odds to the logistical regression formulae. Moreover, the glabella, mastoid process and nuchal crest showed the highest classification accuracies for all the groups, which is similar to findings from other studies $[5,8,23]$. The high and moderately high, positive polyserial correlations between the craniometric (e.g., mastoid height and basion-nasion length) and ordinal variables (e.g., mastoid and glabella) suggest a strong relationship between size and shape of the cranium (Tables 6-7), which corroborates findings from a North American study assessing the accuracy, correlation and corroboration of metric and nonmetric sex estimation [12]. While craniometric analyses for sex estimation are less subjective, rigorous statistical analyses conducted with morphological data can yield comparable accuracies and convey comparable information; similar results were also documented in North America [11, 24].

Low classification accuracies were achieved when Walker [5] was applied to modern South African crania, indicative of different cranial morphologies between North Americans and South Africans. Furthermore, the high frequency of intermediate traits for males and females, demonstrated decreased sexual dimorphism in the South African population. Other studies, using craniometrics, have also suggested that South Africans display 
less sexual dimorphism than their North American counterparts [9-11]. Both the low validation accuracy and the frequency distribution of traits reinforced the need for population-specific formulae for sex estimation.

Sexual dimorphism is population specific due to the differences in geographical location, as well as in the evolutionary influences and experiences of these groups [23, 25, 26]. Thus, the standards derived from the South African population increased overall classification accuracies. The best results were acquired when the modified ordinal logistic regression equations were used to classify the modern South African individuals into males and females. When analysing the trait score frequencies of each ancestry and sex groups, white males continuously achieved the highest scores, especially for the glabella, mastoid process and nuchal crest. Furthermore, black females obtained lower scores than white females, particularly for the glabella. While white females still showed more feminine scores than either of the male groups, they demonstrated numerous intermediate scores as well, which shows a similar pattern to the scores shown by black males (Table 5). The increased robusticity of the white males, as suggested by the higher scores, and the more gracile features of the black females, as seen in the lower scores, indicated that these two groups are most distinctive from the others. The numerous intermediate scores obtained by white females and black males, results in the overlap between the two groups that is responsible for the consistently lower classification accuracies. In order to successfully utilise the Walker [5] method in South Africa population- and ancestry-specific equations were created.

\section{Conclusion}

Despite recent developments in population-specific standards for South Africans, few researchers address the accuracy of morphological methods. Differences in sexual dimorphism between the South Africans and other populations may invalidate sex estimation techniques when data sources are based on populations with different geographical and ancestral origins. The current study modified the Walker [5] formulae for use in modern South Africans, which increased overall classification accuracies. Results of the current study were almost identical to the outcomes produced from the original Walker [5] results and comparable to accuracies associated with metric sex estimation; thus, the modified formula offers a reliable and valid sex estimation technique in South Africa.

\section{Acknowledgments}

The authors would like to thank Marius Loots (Department of Anatomy, University of Pretoria) for assistance with the Pretoria bone collection. This research was funded by the National Research Foundation 
(NRF). Any opinions, findings and conclusions or recommendations expressed in the material are those of the authors and therefore the NRF does not accept any liability in regard thereto.

\section{Ethical standards}

Ethical clearance for this study was obtained from the Student Ethics Committee (s123/2012), Faculty of Health Sciences, University of Pretoria. The skeletal material was handled under the Human Tissue Act 61 of 2003 and in accordance with the Declaration of Helsinki of 1975, as revised in 2000 and 2008.

\section{Erratum to: Sexual dimorphism in cranial morphology among modern South Africans}

Gabriele Christa Krüger, Ericka N. L’Abbé, Kyra E. Stull, Michael W. Kenyhercz

Erratum to Int J Legal Med DOI 10.1007/s00414-014-1111-0

Errors were inadvertently made in the footnotes of Table 9 and Table 10 of this paper. The footnotes for both tables should read "resulting values larger than zero (0) refer to a female individual and less than zero $(0)$ indicate a male individual" (and not, as published "larger than zero (0) refer to a male individual and less than zero (0) indicate a female individual").

Erratum to: Sexual dimorphism in cranial morphology among modern South Africans (DOI 10.1007/s00414-014-1111-0) was published online 29 July 2015 and was given the DOI:10.1007/s00414015-1233-z • 


\section{References}

1. Loth SR, İşcan MY (2000) Sex Determination. In: Siegel J, Knupfer G, Saukko P (ed) Encyclopedia of Forensic Sciences. Academic Press, Waltham, pp 252-260

2. Gapert R, Black S, Last J (2008) Sex Determination from the Occipital Condyle: Discriminant Function Analysis in an Eighteenth and Nineteenth Century British Sample. Am J Forensic Anthropol 2008 138:384-394

3. Aḉsádi G, Nemeskéri J (1970) History of Human Life Span and Mortality. Akademiai Kiado, Budapest, pp 346

4. Buikstra JE, Ubelaker DH (1994) Standards for Data Collection from Human Skeletal Remains. Library of Congress Cataloging in Publication Data, Arkansas, pp 15-46

5. Walker PL (2008) Sexing Skulls Using Discriminant Function Analysis of Visually Assessed Traits. Am J Forensic Anthropol 136:39-50.

6. Garvin HM (2012) Adult Sex Determination: Methods and Application. In: Dirkmaat DC (ed) A Companion to Forensic Anthropology. Wiley-Blackwell, United Kingdom, pp 239-247

7. Brickley M (2004) Determination of Sex from Archaeological Skeletal Material and Assessment of Parturition. In: Brickley M, McKinley JI (ed) Standards for Recording Human Remains. BABAO, Southampton, UK, pp 23-25

8. Ramsthaler F, Kettner M, Gehl A, Verhoff MA (2010) Digital Forensic Osteology: Morphological Sexing of Skeletal Remains using Volume-Rendered Cranial CT Scans. Forensic Sci Int 195:148-152

9. McDowell JL, L’Abbé EN, Kenyhercz MW (2012) Nasal aperture shape evaluation between black and white South Africans. Forensic Sci Int 222 (1-3): 397e1-397e6

10. Ousley S, L’Abbé EN (2010) Craniometric variation in South African and American blacks. Proceedings of the $62^{\text {nd }}$ Annual Meeting of the American Academy of Forensic Sciences Seattle, WA, pp 377-378

11. L'Abbé EN, Kenyhercz M, Stull KE, Keough N, Nawrocki S (2013) Application of Fordisc 3.0 to explore differences among crania of North American and South African blacks and whites. J Forensic Sci 58(3): $1579-1583$

12. Kenyhercz MW, Klales AR, Fredette SM and Dirkmaat DC (2012) Metric and Non-Metric Assessments of Sex: Accuracy, Correlation and Corroboration. Proceedings of the $64^{\text {th }}$ Annual Meeting of the American Academy of Forensic Sciences Atlanta, GA, pp 406-407

13. L'Abbe EN, Loots M, Meiring JH (2005) The Pretoria Bone Collection: A modern South African skeletal sample. HOMO 56:197-205

14. Vance VL, Steyn M, L'Abbe EN, Becker PJ (2010) A Cross-Sectional Analysis of Age Related Changes in the Osteometric Dimensions of Long Bones in Modern South Africans of European and African Descent. Forensic Sci Int 199:11.e1-110.e9

15. L'Abbé EN, Steyn M (2012) The Establishment and Advancement of Forensic Anthropology in South Africa. In: Dirkmaat DC (ed) A Companion to Forensic Anthropology. Wiley-Blackwell, United Kingdom, pp 626-638

16. Banerjee M, Capozzoli L, McSweeney, Debajyoti S (1999) Beyond Kappa: A Review of Interrater Agreement Measures. Can J Stat 27(1):3-23 
17. Landis JR, Koch GG (1977) The Measurement of Observer Agreement for Categorical Data. Biometrics 33(1):159-174

18. Taylor, R (1990) Interpretation of the Correlation Coefficient: A Basic Review. J Diagn Med Sonog 1:3539

19. Dawson-Saunders B, Trapp RG (1994) Basic \& Clinical Biostatistics, $2^{\text {nd }}$ edn. Appleton \& Lange, Norwalk, CT, pp. 210-231

20. Kachigan SK (1991) Multivariate Statistical Analysis: A Conceptual Introduction, $2^{\text {nd }}$ edn. Radius Press, New York, pp. 216-235

21. Anderson JY, Trinkaus E (1998) Patterns of Sexual, Bilateral and Interpopulational Variation in Human Femoral Neck-shaft Angles. J Anat 192:279-285

22. Spradley MK, Jantz RL (2011) Sex Estimation in Forensic Anthropology: Skull Versus Postcranial Elements. J Forensic Sci 56(2):289-296

23. Garvin HM, Sholts SB, Mosca LA (2014) Sexual dimorphism in human cranial trait scores: Effects of population, age, and body size. Am J Phys Anthropol 154:259-269

24. Hefner JT, Spradley MK, Anderson B (2014) Ancestry Assessment Using Random Forest Modeling. J Forensic Sci 59(3):583-9

25. Franklin D, Cardini A, Flavel A, Marks MK (2014) Morphometric analysis of pelvic sexual dimorphism in a contemporary Western Australian population. Int J Legal Med 128(5):861-72

26. Macaluso PJ, Lucena J (2014) Estimation of sex from sternal dimensions derived from chest plate radiographs in contemporary Spaniards. Int J Legal Med 128(2):389-95 